\title{
Antioxidant Activity, Bioactive Compounds and Antimicrobial Effect of Mushrooms Extracts
}

\author{
Georgeta FIDLER $^{1,2)}$, Alina BUTU²), Steliana RODINO ${ }^{1,2)}$, Marian BUTU ${ }^{2)}$, \\ Petruta C. CORNEA ${ }^{1)}$ \\ 1)University of Agronomic Sciences and Veterinary Medicine, Bucharest, Romania \\ ${ }^{2)}$ National Institute of Research and Development for Biological Sciences, Bucharest, Romania \\ *Corresponding author, e-mail: alina_butu@yahoo.com
}

Bulletin UASVM Animal Science and Biotechnologies 72(1) / 2015

Print ISSN 1843-5262; Electronic ISSN 1843-536X

DOI:10.15835/buasvmcn-asb:10922

\begin{abstract}
Ganoderma applanatum and Flammulina velutipes are known for their nutritional value. In the present study was tested their antimicrobial and antioxidant capabilities. Due to the resistance of pathogens to synthetic agents, there is a real need for new natural products with practical utility. Alcoholic extracts of macromycetes' mycelial biomass, obtained in three different culture media were investigated for antimicrobial potential against grampositive and gram-negative bacteria, namely Escherichia coli, Bacillus cereus, B. subtilis, Staphylococcus aureus, Enterococcus faecalis, Pseudomonas fluorescens, and Enterobacter cloacae. Alcoholic extracts of mycelial biomass obtained in medium prepared with wine yeast had a higher inhibitory activity compared to the other two extracts, which had reduced inhibitory activity. Both antimicrobial and antioxidant capacity was dependent on the growth medium of mycelia biomass. The concentration of phenolic compounds directly contributed to the antioxidant action.
\end{abstract}

Keywords: antimicrobial, antioxidant activity, bioactive compounds, mushrooms, DPPH

\section{INTRODUCTION}

Due to the large diversity of pathogenic microorganisms and their acquired resistance to antibiotics, scientists have sought solutions in natural vegetal resources rich in bioactive compounds with antimicrobial properties having a wide area of practical applications, in human and veterinary medicine and nutrition, and plant protection, also (Rodino et al., 2014). Among these vegetal resources, the macromycetes can be an alternative source of new antimicrobials and antioxidants for pharmaceutical use.

Macromycete mushrooms are well known for their nutritional and culinary properties, being used as natural medicines for people of all ages. Besides these qualities, they are also recognized as a source of biologically active compounds with medicinal value, possessing anticancer, antiviral, hepatoprotective, hypocholesterolemic and immunoprotective properties (Rathee et al., 2012).

There is a great number of references in the literature on some mushrooms such as Trametes versicolor, Ganoderma applanatum and G. lucidum, Laetiporus sulphureus, Flammulina velutipes, which proved to be an excellent source of natural products with therapeutic properties. These mushrooms can offer a wide variety of bioactive compounds that possess significant antimicrobial and antioxidant activities (Sławińska et al., 2013; Siljegovic et al., 2011). Therefore, mushrooms are rich sources of natural antibiotics and the extracts of the mycelium and fruiting bodies of different species were previously reported to present antimicrobial activity. 
In this paper, is presented an overview of the antimicrobial and antioxidant properties of two mushroom extracts with special highlight on some of the bioactive compounds responsible for the antimicrobial properties.

\section{MATERIALS AND METHODS}

Macromycete species considered were commercial strains of Flammulina velutipes and Ganoderma applanatum isolated from natural sources. To obtain mycelial biomass, mycelial discs grown in Petri dishes were inoculated into 3 types of liquid medium (medium prepared according to Hwang et al. (2008), medium prepared with extract of sorghum deposit obtained after bioethanol production and medium prepared with yeast wine). After inoculation, the recipients were incubated at $25^{\circ} \mathrm{C}$ on the rotary shaker at $125 \mathrm{rpm}$ for 10 days. Biomass obtained from each liquid medium was filtered and weighed. Alcoholic extracts were obtained by grinding and sonication of the mycelium biomass in alcohol $70^{\circ}$ (ratio biomass : alcohol was 1:10), centrifuged for 15 minutes at $5000 \mathrm{rpm}$. The supernatant was used for the determination of the antimicrobial activity against E. coli, B. cereus and B. subtilis, S. aureus, E. faecalis, $P$. fluorescens and E. cloacae (belonging to the collection of Biotechnologies department of the National Institute of Research and Development for Biological Sciences and Biotechnologies Faculty, UASVM Bucharest). Antimicrobial activity testing was evaluated using disk diffusion method. The concentration of polyphenolic compounds in the mushrooms extracts, expressed as gallic acid equivalents (GAE) was determined using the Folin Ciocalteau reagent as described by de Oliveira et al. (2012) with some modifications, $100 \mu \mathrm{l}$ extract $+1 \mathrm{ml}$ water $+100 \mu \mathrm{l}$ Folin Ciocalteau. The mixture was added $300 \mathrm{ml}$ of sodium carbonate of $20 \%$ concentration.

Antioxidant capacity was determined using DPPH solution $0.1 \mathrm{mmol} / \mathrm{L}$ as described in a previous study by Butu et al. (2014a), as follows: $0.5 \mathrm{ml}$ of the extract was added over $1 \mathrm{~mL}$ of DPPH $0.1 \mathrm{mmol} / \mathrm{L}$ (solution prepared daily and protected from light). The mixture was vigorously stirred and incubated at room temperature for 30 minutes, and then the optical density was measured at $515 \mathrm{~nm}$ wavelength using methanol as a control. Control sample contained all components mentioned above except hydroalcoholic extract.
Optical density of DPPH in methanol solution has not undergone major changes during the entire analysis. DPPH radical destruction capacity was calculated using the following equation:

$$
A A_{D P P H}(\%)=\frac{O D_{\text {control }}-O D_{\text {sample }}}{O D_{\text {control }}} \times 100
$$

where, $\mathrm{OD}_{\text {control }}=$ the optical density of the control, and $\mathrm{OD}_{\text {sample }}^{\text {control }}=$ the optical density of the sample with extract.

\section{RESULTS AND DISCUSSION}

Antimicrobial activity. This study shows that bazidimiocetes possess antimicrobial activity. It is known that both fruiting bodies and mycelia of several species, such as Lactarius sp. (Bergendorf et al., 1988; Anke et al., 1989), Boletus sp. and Cortinarius sp. (Lee et al., 1999; Nicholas et al., 2001) and Laetiporus sulphureus (Fidler et al., 2013) are containing antimicrobial substances and some of the results obtained in the present study are consistent with previous studies reported in literature (Rosa et al., 2003; Suay et al, 2000).

The results of the present research indicated that alcoholic extracts obtained from mycelium biomass, developed on each tested liquid medium, have the ability to inhibit strains of gram-positive and gram-negative bacteria, Escherichia coli, Bacillus cereus, B. subtilis, Staphylococcus aureus, Enterococcus faecalis, Pseudomonas fluorescens, and Enterobacter cloacae. The extracts' activity was compared to the negative control one $\left(70^{\circ}\right.$ alcohol).

In most cases, the alcoholic extracts of mycelial biomass obtained in medium prepared with wine yeast had a mean inhibitory activity tested compared with extracts of mycelial biomass obtained in other medium, where they had a reduced inhibitory activity or almost inexistent (Tab. 1).

Antioxidant activity. Other previous studies also concluded that mushrooms present powerful antioxidants. For the estimation of antioxidant activity, one of the commonly used mechanisms of inhibition of lipid oxidation is capturing free radicals (Butu et al., 2014b) Radical scavenging activity (RSA) of the mushroom extracts was tested against 1,1-Diphenyl-2-picryl-hydrazyl; (DPPH) which is a stable free radical with a 
Tab. 1. Antimicrobial activity of alcoholic extracts
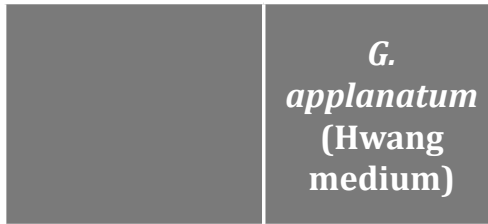

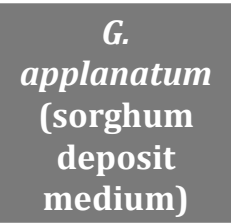

F
velutipes
(Hwang
medium)

F. velutipes

(wine yeast medium)

\begin{tabular}{|c|c|c|c|c|c|c|}
\hline E. coli & + & + & ++ & - & - & ++ \\
\hline S. aureus & - & + & - & - & ++ & - \\
\hline E. fecalis & - & - & - & - & - & ++ \\
\hline P. fluorescens & - & + & ++ & - & - & + \\
\hline E. cloacae & - & ++ & + & - & + & ++ \\
\hline B. cereus & + & ++ & ++ & - & - & - \\
\hline B. subtilis & - & ++ & ++ & - & + & ++ \\
\hline
\end{tabular}

characteristic sorption at $515 \mathrm{~nm}$. Keles et al. (2011) demonstrated that extracts of $F$. velutipes could present antioxidant activity through several mechanisms of free radical scavenging and reducing power, mechanisms that contributed to existence of total phenolic compounds in extracts. The results of the present study indicated DPPH radicals were reduced in all cases, but in different proportions. Comparing the values obtained in evaluating the antioxidant activity was observed that the antioxidant activity of hydroalcoholic extract obtained from mycelial biomass resulting in medium prepared with wine yeast is higher than that prepared with sorghum deposit. The concentration of polyphenols and antioxidant capacity was dependent on the growth medium of mycelia biomass (Tab. 2).

This study suggests that the antioxidant activity of ethanolic extracts from mushrooms is due to phenolic compounds content. In research conducted by Slawinska et al. (2013) was reported that both the solvent and the extraction method influence total phenolic content and antioxidant activity of the extracts. In our case, this was due to the mycelia growth medium composition.

\section{CONCLUSION}

Mushrooms present a valuable source of antimicrobial and antioxidant agents, but require further studies to optimize the growth conditions and extraction methods to recover larger amounts of biologically active compounds. In conclusion, the results are promising, alcoholic extracts tested against pathogens had inhibitory effects depending on the culture media used for obtaining the mycelium biomass. The results of this study confirm the potential of macromycetes as an antimicrobial and an antioxidant agent.

Potential therapeutic implications of mushrooms are enormous, but detailed mechanisms of the various health benefits still require investigation. Exploring antioxidant and antimicrobial activity of mushrooms and isolation of active compounds with therapeutic value remains a challenge and still much work is to be done in this area of research.

Tab. 2. The concentration of polyphenols and antioxidant capacity of alcoholic extracts from mushroms

\begin{tabular}{|l|c|c|c|c|c|c|}
\hline & $\begin{array}{c}\text { G. } \\
\text { applanatum } \\
\text { (Hwang } \\
\text { medium) }\end{array}$ & $\begin{array}{c}\text { G. applanatum } \\
\text { (sorghum } \\
\text { deposit } \\
\text { medium) }\end{array}$ & $\begin{array}{c}\text { applanatum } \\
\text { (wine yeast } \\
\text { medium) }\end{array}$ & $\begin{array}{c}\text { F. velutipes } \\
\text { (Hwang } \\
\text { medium) }\end{array}$ & $\begin{array}{c}\text { F. velutipes } \\
\text { (sorghum } \\
\text { deposit } \\
\text { medium) }\end{array}$ & $\begin{array}{c}\text { Felutipes } \\
\text { (wine yeast } \\
\text { medium) }\end{array}$ \\
\hline $\begin{array}{l}\text { Antioxidant } \\
\text { activity }\end{array}$ & $81.466 \pm$ & $69.141 \pm 0.623$ & $74.134 \pm$ & $51.552 \pm$ & $41.374 \pm$ & $74.044 \pm$ \\
DPPH \% & 1.022 & 0.206 & 0.539 & 1.297 & 0.608 \\
\hline $\begin{array}{l}\text { Polifenols } \\
\text { mg.GAE /g }\end{array}$ & $68.348 \pm$ & $41.209 \pm 0.445$ & $67.331 \pm$ & $33.350 \pm$ & $61.805 \pm$ & $125.121 \pm$ \\
\end{tabular}


Acknowledgements. This paper was published under the frame of European Social Fund, Human Resources Development Operational Programme 2007-2013, project no. POSDRU/159/1.5/S/13.

\section{REFERENCES}

1. Anke T (1989). Basidiomycetes: A source for new bioactive secondary metabolites. Prog Ind Microbiol 27: 51-66

2. Bergendorf O, Sterner O (1988). The sesquiterpenes of Lactarius deliciosus and Lactarius deterrimus. Phytochemistry 27: 97-100.

3. Butu M, Rodino S, Golea D, Butu A (2014a). Screening of the antioxidant capacity and total phenolic content of three native plants. Digest J. of Nanomaterials and Biostructures 9(1): 337-345.

4. Butu M, Rodino S, Butu A, Butnariu M (2014b). Screening of bioflavonoid and antioxidant activity of Lens culinaris medikus. Digest J. of Nanomaterials and Biostructures 9(2): 519-529.

5. Fernandes de Oliveira AM, Pinheiro LS, Pereira CKS, Matias WN, Gomes RA, Chaves OS, MF Vanderlei de Souza, Nóbrega de Almeida R, Simões de Assis T (2012). Total Phenolic Content and Antioxidant Activity of Some Malvaceae Family Species. Antioxidants, 1: 33-43.

6. Fidler G, Popa G, Butu A, Rodino S, Cornea CP (2013). In vitro cultivation of Laetiporus sulphureus and evaluation of its antimicrobial properties. Scientific Bulletin. Series F. Biotechnologies XVII: 11-15.

7. Hwang H S, Lee SH, Baek YM, Kim SW, Jeong YK, Yun JW (2008). Production of extracellular polysaccharides by submerged mycelial culture of L. sulphureus var. miniatus and their insulinotropic properties. Appl. M. Biotech.78: 419-429.
8. Keleş A, Koca I, Gençcelep H (2011). Antioxidant Properties of Wild Edible Mushrooms. Food Processing \& Technology, 2-6.

9. Lee SJ, Yeo WH, Yun BS, Yoo ID (1999). Isolation and sequence analysis of new peptaibol, Boletusin, from Boletus spp. J Pept Sci 5: 374-378.

10. Nicholas GM, Blunt JW, Munro, MHG (2001). Cortamidine oxide, a novel disulfide metabolite from the New Zealand Basidiomycete (mushroom) Cortinarius species. J Nat Prod 64: 341-344.

11. Rathee S, Rathee D, Kumar V, Rathee P (2012). Mushroom as therapeutic agents. Brazilian Journal of Pharmacognosy, 22(2): 459-474.

12. Rodino S, Butu M, Petrache P, Butu A, Cornea CP (2014). Antifungal activity of four plants against Alternaria alternata. Scientific Bulletin. Series F. Biotechnologies, XVIII: 60-65.

13. Rosa LE, Machado KMG, Jacob CC, Capelari M, Rosa CA, Zani CL (2003). Screening of Brazilian Basidiomycetes for antimicrobial activity. Mem Inst Oswaldo Cruz Rio de Janerio 98: 967-974.

14. Siljegovic JD, Stojkovic DS, Nicolic MM, Glamoclija JM, Sokovic MD, Ciric AM (2011). Antimicrobial activity of aqueous extract of L. sulphureus (Bull: Fr). Mur.Proc.Nat. Sci. 120: 297-303.

15. Sławińska A, Radzki W, Kalbarczyk J (2013). Antioxidant activities and polyphenolics content of Flammulina velutipes mushroom extracts. Herba polonica 59(3): 2636.

16. Suay I, Arenal F, Asensio FJ, Basilio A, Cabello MA, Diez MT, Garcia JB, Val AG, Gorrochategui J, Hernandez P, Pela'ez F, Vicente MF (2000). Screening of Basidiomycetes for antimicrobial activites. Antonie Van Leeuwenhoek 78: 129-139. 